REVISTA CHILENA DE LITERATURA

Abril 2009, Número 74, 99 - 121

\title{
UNA POÉTICA DE LAS RUINAS: TESTIMONIO Y ALEGORÍA DE ANÍBAL QUIJADA
}

\author{
Jaume Peris Blanes \\ Universitat de València \\ jaume.peris@gmail.com \\ RESUMEN / ABSTRACT
}

El texto de Aníbal Quijada Cerco de púas ejemplifica la doble vinculación de los testimonios del exilio chileno. Por una parte, éstos debieron inscribirse en las estrategias internacionales de denuncia contra la dictadura militar y, por otra, la comunidad cultural latinoamericana hizo de los testimonios un elemento esencial para la redefinición del concepto mismo de lo literario. El testimonio de Quijada desarrolla, en ese contexto, unas estrategias narrativas y de representación que alejan su textura de la mayoría de los testimonios de la época.

Palabras Clave: testimonio, alegoría, dictadura militar chilena, campos de concentración, Casa de las Américas.

Abstract: The text of Anibal Quijada Cerco de puias, is a good example of the double filiation of the testimonies of chilean exile. In one hand, these testimonies had a close relationship with the international protest against the military rule and, one the other hand, the cultural community made them appear as a main element in the crise of the concept of literature. The author focuses in the strategies used by the text of Quijada in that turbulent context.

KEY WORDS: Testimony, allegory, military dictatorship, concentration camps, Casa de las Américas. 


\section{INTRODUCCIÓN}

Entre los testimonios publicados en el exilio por los supervivientes de la represión militar chilena, el texto de Aníbal Quijada Cerco de Púas (1977) destaca por su sutil incorporación de procedimientos explícitamente literarios a una forma textual que, en la mayoría de los casos, ha rechazado su vinculación con el discurso literario para alinearse sin ambages con la denuncia política.

El propósito de este artículo es analizar el modo en que los testimonios del exilio y, especialmente, el de Quijada, debieron asumir de forma conflictiva esa doble filiación: por una parte, la de la militancia política en el exilio; por otra, la de las nuevas literaturas testimoniales latinoamericanas. El texto de Quijada es un objeto privilegiado para analizar esa problemática porque 1) fue galardonado con el premio literario más prestigioso de América Latina en el momento, en la novedosa categoría de testimonio, 2) hace dialogar la escritura testimonial con breves piezas de ficción y poemas y, en definitiva, inscribe el testimonio en un trabajo explícitamente literario con el lenguaje.

Para ello, el artículo contextualizará y analizará críticamente esa doble filiación que marca los caminos del testimonio chileno en los años setenta, y la forma en que el texto de Quijada responde a las expectativas de las luchas del exilio y del campo literario latinoamericano. En su último tramo, analizará detenidamente las estrategias narrativas y figurativas utilizadas por Quijada en su texto y, apoyándose en la concepción de la 'alegoría' desarrollada por Avelar, tratará de definir el modo en que este testimonio alude a la experiencia histórica de la represión chilena.

Metodológicamente, el autor se valdrá del análisis textual del libro de Quijada, sirviéndose de las herramientas metodológicas desarrolladas en trabajos anteriores (Unnold y Peris Blanes, La imposible...), y relacionará dicho texto con intervenciones contemporáneas, describiendo el modo en que el texto dialoga con otras formas discursivas del momento, de acuerdo con la perspectiva histórica y social del testimonio trazada por Wieviorka:

"El testimonio, sobre todo cuando se halla integrado en un movimiento de masas, expresa, además de la experiencia individual, el o los discursos que tiene la sociedad, en el momento en que el testigo cuenta su historia, sobre los acontecimientos que el testigo ha vivido. Dice, en principio, lo que cada individuo, cada vida, cada experiencia de la Shoa tiene de irreductiblemente único. Pero lo dice con las palabras que son propias de la época en que testimonia, 
a partir de un cuestionamiento y de unas expectativas que son también contemporáneas de su testimonio, asignándole finalidades dependientes de intereses políticos o ideológicos, contribuyendo así a crear una o más memorias colectivas, erráticas en su contenido, en su forma, en su función y en la finalidad, explícita o no, que ellas se asignan" (13).

\section{EL TESTIMONIO ENTRE LA VANGUARDIA POLÍTICA Y LA VANGUARDIA ESTÉTICA}

En 1977, la Casa de las Américas galardonó a Cerco de púas con su prestigioso premio literario. Lo hizo en la categoría de Testimonio, creada solo unos años antes para hacer frente a la aparición de nuevos textos que no calzaban en las definiciones tradicionales de lo literario, sino cuyo valor se hallaba, además de en su escritura, en el modo en que daban cuenta de la realidad latinoamericana.

La entrega del premio indicaba hasta qué punto los testimonios de los campos de concentración chilenos se hallaban inscritos en dos procesos simultáneos. En primer lugar, tras el golpe militar, la denuncia pública de la dictadura se convirtió en una de las actividades centrales de la izquierda chilena en el exilio y los testimonios de los supervivientes adquirieron una importancia central en ellas. Relatar su experiencia en los campos suponía, en ese contexto, sumarse al combate ${ }^{1}$. En segundo lugar, ello ocurría en un contexto de gran efervescencia cultural en el que la vanguardia literaria y artística de América Latina no solo había abrazado un ideario político muy cercano al del proyecto frustrado de la Unidad Popular, sino que además, había llevado a cabo una redefinición del concepto mismo de 'lo literario', en el que las escrituras testimoniales pasarían a valorarse como tales.

De ese modo, a la vez que la izquierda chilena acogía la escritura de relatos testimoniales como nueva forma de combate, la vanguardia cultural reivindicaba esas escrituras políticas como pertenecientes al nuevo orden de lo literario. Los testimonios, que pocos años antes carecían de cualquier tipo de presencia en el discurso político y en el literario, aparecían ahora como elementos fundamentales para ambos.

Puede hallarse una descripción más detallada de ese proceso en Peris Blanes, Historia del testimonio chileno... 


\section{REFIGURAR LA COMUNIDAD QUEBRADA}

El libro de Quijada constituye aún hoy, en el panorama de los testimonios escritos por los supervivientes en el exilio, una hermosa y singular rareza. Se trataba, por una parte, de un testimonio en el sentido fuerte del término, es decir, del relato que un superviviente hace de su experiencia del encierro un tiempo después de haber sido liberado. Pero Quijada dividió Cerco de púas en dos partes diferenciadas: una propiamente testimonial, en la que reconstruía algunas escenas de su vida en el campo hasta su salida en libertad condicional y otra, en la que reunía algunos textos de apariencia ficcional en torno a la figura metafórica del perro, en los que se narraban diversas relaciones de perros con sus amos detenidos en los campos.

Más allá de ese estructura doble, lo singular es que Quijada organizó su relato a través de procedimientos literarios muy explícitos que, sin restarle autenticidad ni fiabilidad, complejizaron el discurso testimonial, explorando las potencialidades simbólicas de ciertos elementos de la iconografía concentracionara hasta elevarlos a un estatuto metafórico o alegórico. El texto de Quijada carece de una narratividad tan trabada como en el caso del testimonio magistral de Hernán Valdés, Tejas Verdes. Diario de un campo de concentración en Chile. Sin embargo, esa ausencia de continuidad causal entre las diferentes escenas hace que cada una de ellas se cierre sobre sí misma, adquiriendo una fuerte impronta metafórica de la que careció la mayoría de los testimonios. La atmósfera de cada uno de los capítulos produce una suerte de temperatura emotiva que impregna todos los acontecimientos convocados por la narración.

A pesar de su singularidad estética, el texto de Quijada comparte buena parte de los elementos que hicieron de los testimonios de los supervivientes textos fundamentales de la lucha del exilio. En el esfuerzo de construir un amplio frente internacional de oposición al régimen militar, muchos de los supervivientes ofrecieron públicamente su relato en comisiones y tribunales internacionales que trataban de determinar el alcance de los métodos represivos en de la dictadura. Algunos de los líderes políticos de la Unidad Popular en el exilio llegaron incluso a situar a los supervivientes que ofrecían su testimonio "entre los mejores combatientes de la causa antifascista chilena" 2 .

2 Así lo hacía Luis Corvalán, al prologar el testimonio de Rolando Carrasco (5). 
La mayoría de las estrategias retóricas de los testimonios estaban, de hecho, relacionadas con la misión política que las luchas del exilio parecían haberles impuesto. A saber, resguardar en la narración los elementos de la experiencia social que habían sido fundamentales en el proyecto de la Unidad Popular y que la violencia de la dictadura había arrasado. Para ello, los supervivientes representaron de múltiples formas sus valores morales e ideológicos $\mathrm{y}$ construyeron escenas en las que éstos encarnaban de un modo $\mathrm{u}$ otro.

Recurrieron, para ello, a dos tropos fundamentales: por una parte, propusieron su experiencia de los campos de concentración como una metonimia de la experiencia colectiva de toda la comunidad política chilena. Por otra, aludieron a través de una serie de metáforas narrativas al funcionamiento de esa comunidad de las que se sentían parte y representante y que la dictadura militar se había propuesto hacer desaparecer.

La metaforización narrativa de esas formas de la comunidad en peligro o ya perdidas se realizó, fundamentalmente, a través de dos estrategias. Algunos textos aludieron a ellas 'rescatando' los modos de interacción de los grupos políticos de izquierdas antes de que sus militantes fueran detenidos por los aparatos represivos: es decir, describiendo sus prácticas y la forma de articulación de sus colectivos. La mayoría, sin embargo, aludieron a la idea de comunidad, reconstruyendo la vida cotidiana en los campos como un modo de resistencia precaria y desolada, pero de importantes efectos frente a la dinámica deshumanizadora en que el sistema represivo inscribía a los detenidos.

Pero esa voluntad de aludir a la experiencia de la comunidad quebrada no solo creó imágenes de las relaciones colectivas sino que permeó, en muchos casos, la propia voz testimonial y la sintaxis del testimonio. Éste se enfrentaba, de hecho, a una aparente contradicción: representar desde la voz de un solo sujeto una experiencia que, se insistía constantemente, pertenecía a toda una comunidad. La mayoría de los supervivientes abordaron de un modo u otro ese problema, y algunos de ellos se vieron en la necesidad de dotar a sus relatos testimoniales de una gran complejidad enunciativa a través de la cual dar cuenta de una experiencia que desbordaba la de su propia subjetividad y que englobaba las experiencias sufridas por otros sujetos.

Entre ellos, Cerco de púas ensayó en sus escenas diferentes modos de aludir a ello:

Los primeros días fueron terribles, camarada. ¿Sabe usted que este galpón comenzó a recibir presos desde la misma mañana del día 
once? Eran arrojados aquí, con las manos amarradas a la espalda, con alambre. Imagínese, el tanque, adentro, casi cubriendo todo el frente como usted lo vio, repleto de guardias, y el resto un peladero frío y malsano. (...) Le cuento solamente lo que vi, lo que a mí me sucedió (61-62, la cursiva es nuestra).

Ese fragmento no se halla inscrito, en la narración, en ninguna escena de diálogo. Es decir, todos los elementos que hacen referencia al receptor y que por tanto ponen el énfasis en la función fática y en el acto comunicativo estaban interpelando directamente al lector, y poniendo el acento en la relación específica que se establecía entre el superviviente y aquel a quien iba dirigido su testimonio. De algún modo, esa señalización del estatuto comunicativo del testimonio - es decir, de su ser enunciado para alguien-aludía al carácter comunicable y compartible de la experiencia que relataba y a la presencia de una comunidad en el interior de la cual adquiría esos atributos.

De hecho, la idea de 'camarada' apunta precisamente a esa copertenencia a un mismo sistema de referencias políticas, esto es, a una identidad social común. Pareciera como si la experiencia vivida en los campos se hiciera inteligible para el superviviente, y por ello enunciable en tanto tal, a partir de su inclusión en ese espacio imaginario y políticamente marcado de pertenencia colectiva. Es en el marco de ese espacio simbólico donde la experiencia narrada puede adquirir sentido.

Así, esos marcadores textuales que dirigen la representación de la experiencia a un receptor imaginario pero perteneciente a un mismo ámbito comunitario ficcionalizan un espacio para la circulación del discurso que en el espacio del exilio internacional se hallaba seriamente deteriorado. De ese modo se enfatizó la funcionalidad del testimonio como rearticulador de los circuitos a través de los cuales la experiencia social podía ser compartida.

Esa era precisamente una de las funciones que estos textos trataban de desempeñar. De hecho, muchos de los supervivientes que decidieron publicar su testimonio pensaban en la posibilidad de dotar de elementos de circulación al exilio chileno, con la esperanza de proporcionarle espacios de reconocimiento que pudieran operar una cierta cohesión en él. Lo cierto es que la constitución de ese espacio simbólico que Quijada se esforzó en metaforizar se vería reforzada no solo por las intervenciones de los grupos de exiliados y de las instituciones internacionales, sino que además contó con la energía de diferentes instituciones culturales latinoamericanas. 


\section{EL TESTIMONIO Y EL CAMPO LITERARIO}

Al premiar Cerco de púas, Casa de las Américas no solo trató de dar mayor visibilidad a la situación de los presos chilenos y de implicarse en las estrategias de denuncia de los exiliados chilenos, sino que además formalizó institucionalmente la vinculación entre los testimonios de los supervivientes y la redefinición del sistema literario que estaba teniendo lugar en el campo cultural latinoamericano ${ }^{3}$.

La inclusión de los testimonios en el paradigma de lo literario y su aceptación como un modo de representación capaz de dar cuenta de espacios de la realidad a los que la literatura ficcional no llegaba no fue casual. Fue, por el contrario, el resultado del intenso debate en torno a la figura del intelectual vivido por la comunidad cultural latinoamericana en los años sesenta y que, no sin virulencia, giró en torno a la relación entre los escritores, las obras literarias y los procesos sociales de corte revolucionario que estaban teniendo lugar en Cuba y, se decía, en poco tiempo tendrían lugar en el resto del continente.

De ese debate salieron seriamente dañadas tanto las poéticas del realismo socialista de la tradición soviética como, más sorprendentemente, las narrativas de los escritores de la llamada 'nueva novela latinoamericana' que, en un principio, habían acompañado la aventura cubana, pero que con el comienzo de la nueva década, y tras diversos enfrentamientos, serían tachados por la oficialidad cubana de vanguardistas burgueses y contrarrevolucionarios. Ello tenía lugar, además, en un contexto de auge del antiintelectualismo, en el que las urgencias políticas del momento parecían desacreditar la idea misma del trabajo intelectual y poner en duda su capacidad revolucionaria per $\mathrm{se}^{4}$.

En ese contexto, el testimonio aparecía como una forma literaria no vinculada a la figura elitista del intelectual y, por tanto, más cercana al tipo de relatos que la experiencia histórica de América Latina parecía demandar. En las conversaciones internas de 1969 que dieron lugar a la inclusión de la

3 Casa de las Américas había premiado, además, el libro de Omar Lara Oh, buenas maneras y el poemario de Hernán Miranda La Moneda y otros poemas, y en 1975 la sección de cuentos premió el libro Definición del olvido de Leopoldo Carvajal. La revista Casa de las Américas, había publicado además numerosos textos de autores chilenos en el exilio.

4 El auge del antiintelectualismo en Cuba en relación con las polémicas sobre la función del intelectual está magníficamente analizada por Claudia Gilman (2003). 
categoría de testimonio en el premio Casa de las Américas se pudo verificar la crisis de la concepción tradicional de 'lo literario', y la conflictiva relación entre su valor artístico y político. Además de reconocer una transformación que ya se estaba dando de facto en la propia creación literaria, Casa de las Américas trataría desde entonces de promover, potenciar y valorar esas nuevas formas de escritura. La categoría de testimonio -frente a otras opciones terminológicas-sirvió en ese momento de indefinición como elemento de articulación y de anclaje de esas nuevas propuestas, legitimadas por fin por una institución y un grupo de intelectuales de gran incidencia en el campo cultural latinoamericano. Señalaba en ellas Ángel Rama:

Existen, entre otras, buenas obras literarias, con interés, que no todas llegan a la calidad de un premio que podríamos mencionar, pero cuyo valor no está solamente en lo literario, sino en lo que testimonian del proceso de la América Latina. (...) Eso me dice que en la América Latina, aunque no se esté premiando una hermosa obra -porque cualquier obra hermosa contribuye al mejoramiento de todos, y al desarrollo de nuestro pueblo-, esa obra es un testimonio del proceso histórico del cual soy partícipe (VVAA 122).

Había en esa discusión una importante indeterminación de los criterios con los que juzgar las obras testimoniales. Que fuera Ángel Rama quien incurría en tal confusión de criterios, quizás el más lúcido de los pensadores de la literatura de la época, ponía al descubierto las dificultades del campo intelectual para pensar el problema de esas escrituras emergentes. Lo que esa dificultad traducía era el desfase entre los modos institucionales de recepción y lectura y las formas concretas que la escritura literaria estaba tomando en la época para responder a una nueva realidad política y social.

El riesgo de que la fuerte vinculación política de los testimonios llevara a soslayar los valores estéticos de las obras hizo que durante años se incluyera en las bases del concurso que "la forma queda a discreción del autor, pero la calidad literaria también es indispensable" (Jorge Fornet 121): dejando, por supuesto, esa 'calidad literaria' fuera de cualquier definición normativa. Ello reafirmaba la ambigüedad de los criterios con los que se juzgaban estos textos y el modo esquivo como se inscribían en el circuito literario. Constituyendo el testimonio la forma textual que servía a los intelectuales revolucionarios para cuestionar el propio concepto de 'lo literario', estos mismos intelectuales recurrían al paradigma de la calidad literaria para marcarle un límite muy poco definido. 
Esa dificultad, y la indecisión en el criterio desde el cual valorar los textos testimoniales, fue extraordinariamente similar a aquella con la que los grandes nombres de la izquierda chilena (Luis Corvalán, Volodia Teitelboim, Gladys Marín, Clodomiro Almeyda...) tuvieron que lidiar al presentar al espacio público internacional y al disgregado exilio chileno los testimonios de los supervivientes de los campos. Ambos se articulaban, de hecho, sobre una retórica, una sintaxis e incluso un léxico bastante similar. Mientras los críticos literarios utilizaban con soltura conceptos provenientes de la sociología, la teoría política o la crítica social, los activistas políticos incorporaban a su discurso vocablos de estética o crítica literaria. Cercados entre esos trasvases lingüísticos, los testimonios hallarían diferentes recorridos para responder a las expectativas que el mundo literario y la comunidad política habían depositado en ellos.

No es extraño, pues, que los mismos testimonios incorporaran en su seno estrategias propias de poéticas más bien alejadas del empuje documental sobre el que todas ellas se sostenían, y que introdujeran elementos que vinculaban sus textos con la tradición literaria. Ello no quita que muchos de los testimonios rechazaran explícitamente su vinculación con la literatura para reforzar, así, su aspiración documental: el hecho de que debieran insistir recurrentemente en ello indicaba, sin embargo, que esa desvinculación no era tan tajante como muchos de los supervivientes pretendieron ${ }^{5}$.

En un texto tan inscrito en la lucha política como Prigué (Rolando Carrasco 1977) por ejemplo, la descripción detallada y rigurosa de la experiencia vivida en los campos se articulaba a un trabajo estético que trataba de hallar la forma lingüística y composicional adecuada para cada fragmento. Valga como ejemplo:

5 Nótese por ejemplo la elegancia (casi literaria) con la que Luis Vega prologaba su testimonio: "Este libro no es una novela aún cuando describe tortuosos y sofisticados complots a corto y largo plazo y tenebrosas maquinarias de quienes, según Erich Fromm, le "tienen miedo a la libertad", y sórdidos sueños y proyectos de dominación mundial propios de novelas de política-ficción. No es más que un pálido reflejo de la realidad del mundo de las dictaduras militares latinoamericanas, en general, y de la chilena en particular. Su credibilidad podría resultar difícil porque siempre la monstruosidad de lo real, de la esquizofrenia social en algunos lugares y momentos, supera la fantasía" (11). 
"Llegamos al primer piso y nos sacan a la calle. Nos organizamos en una formación de a tres. El pavimento brilla mojado. Chispean espejos de vidrios rotos" (21, la cursiva es nuestra).

Era a partir de sugerentes insertos como éste - un perfecto y medido endecasílabo-, que transmutaban una visión concreta en un sintagma de alto valor expresivo, como Carrasco respondía a esa figuración con que Luis Corvalán presentaba su testimonio: "Este libro lo sitúa entre los mejores combatientes de la causa antifascista chilena y como un brillante narrador" (Carrasco 5). El ideologema del talento literario suponía, pues, un plus de valor para los textos en el imaginario de la lucha antifascista en que estos se inscribían.

Pero, más allá de esa inscripción problemática del texto en el paradigma de la denuncia o en el de la elaboración literaria, lo cierto es que ese tipo de elaboración del lenguaje daba otra dimensión al testimonio, desvinculando su forma de la mera transitividad informativa y acercándola, por el contrario, a esa exploración crítica de los propios códigos que caracteriza a lo que llamamos literatura.

Ese compromiso con el lenguaje se hallaba presente en la mayoría de los testimonios del exilio y no necesariamente en aquellos más desvinculados de la urgencia denunciante de los primeros tiempos del exilio. El caso del testimonio ya citado de Valdés, que sirvió de referente y modelo para otros muchos testimonios, revelaba la capacidad de la enunciación testimonial para organizar una narración férrea que a través de un tempo durísimo y de un uso tensado y muy medido de ciertos recursos literarios conseguía una potencia para expresar el horror que parecía reservada a los más sutiles y terribles logros de la historia literaria.

En otro testimonio ejemplar, el de Francisco Reyes, Testigo Presencial (1981), había un progresivo desplazamiento de la enunciación hacia la voz de los personajes que recreaba. Esto es, si en un principio Reyes describía la historia y la desolación de los personajes que habían poblado los campos desde su punto de vista, bien entrado el relato y sin mayores mediaciones nos introducía abruptamente en la voz de algunos de ellos. De ese modo, en capítulos como "El carbonero" o "El choro" asistimos a la reconstrucción ficcional de la voz de los personajes que les dan título, dando cuenta de su propia experiencia de la concentración, de acuerdo con sus modos diferenciados de hablar y sus específicos códigos morales. Ello implicaba, por supuesto, todo un trabajo de elaboración del punto de vista y de reconstrucción ficcional de una voz ajena que se abastecía de procedimientos desarrollados 
en la tradición literaria. La composición caleidoscópica que Reyes ofrecía, de hecho, bebía directamente de las fuentes de las escrituras modernistas -en la acepción anglosajona del término-, desplazándose entre las conciencias de diversos personajes y remedando la particularidad de la voz de cada una de ellas.

\section{LA FRAGMENTACIÓN NARRATIVA: TONO Y METÁFORA}

Cerco de púas fue, quizás, el texto del exilio chileno que articuló de una forma más compleja y eficaz esa doble vinculación del testimonio. Por una parte, como ya se ha visto, trató de construir discursivamente esa comunidad política a la que los discursos del exilio y muchos de los testimonios aludían de un modo mucho más burdo. Ello entronca con su decidida voluntad de dignificar la experiencia y la figura de los detenidos en los campos y de rescatar algunos de sus comportamientos, desde una posición de resistencia ética a la revolución capitalista que estaba teniendo lugar en Chile. Por otra, Quijada trató de movilizar para ello una serie de recursos explícitamente literarios, que en otros testimonios se hallaban también presentes, pero que en el suyo adquirían una relevancia y una profundidad que muy pocos testimonios alcanzaron ${ }^{6}$.

Como se ha señalado anteriormente, el testimonio de Quijada no es una narración cronológica de la vida en el campo, sino que se compone de diferentes escenas sin aparente relación narrativa. Cerco de púas yuxtapone, además, diferentes materiales y formas textuales, ya que a los capítulos propiamente testimoniales, en los que reconstruyen algunas escenas de su vida en el campo, se suman breves cuentos de apariencia ficcional basados en la figura del 'perro' y un largo poema final.

La ausencia de continuidad narrativa entre los diferentes elementos textuales era una característica que lo acerca a la estructura de la mayoría de los testimonios del primer exilio, que habían presentado una narratividad más

6 No es este, ni mucho menos, un juicio de valor negativo sobre la mayoría de los testimonios del exilio ya que, al contrario que buena parte de la crítica, no creo que haya que valorarlos de acuerdo con su adecuación a los criterios propios de la institución literaria. Me refiero precisamente a que Quijada supo articular muy bien esos criterios estéticos a una producción textual que, en muchos casos había privilegiado otro tipo de criterios. 
bien débil (Dorfman). Esa debilidad narrativa, más que un fracaso estético revelaba, en realidad, dos cuestiones fundamentales: que la experiencia de los campos se presentaba totalmente fragmentada a los supervivientes; y que al elaborar narrativamente esa experiencia fragmentada, la mayoría de ellos no consiguió integrar esos elementos disgregados en una narración unitaria.

Se trata de una consideración general y como tal inexacta, pero suficientemente recurrente como para pensar que en esa debilidad narrativa se halló uno de los nudos fundamentales del testimonio, ya que estaba cifrando, de algún modo, la relación que en ellos se establecía entre la experiencia fragmentada, la narración en que se incluía y la subjetividad garante de esa narración y de su potencial sutura. Tratando de dar cuenta de una experiencia catastrófica para el sujeto, no es extraño que quien se hiciera cargo del discurso lo hiciera de forma titubeante, exploratoria, sin capacidad para construir un dispositivo capaz de hacer inteligible, homogéneo y con continuidad narrativa el lenguaje con el que daba cuenta de ello ${ }^{7}$.

Lo singular del texto de Quijada era que consiguió dar una dimensión metafórica a esa fragmentación narrativa, cerrando cada una de las escenas sobre ella misma, a la manera de un relato independiente con su imaginería, su retórica y sus personajes propios, diferentes a los de los demás relatos del libro. La segunda parte (titulada 'Paréntesis sobre perros'), gracias a su apariencia ficcional, presenta una tonalidad casi alegórica. Pero la fuerte irradiación simbólica de ésta se anunciaba ya en las escenas de la primera parte, en las que se describe la vida en el campo y que son propiamente testimoniales. Así, en la descripción de una escena terrible en la que los soldados apalean como escarmiento a un prisionero, se leía lo siguiente:

El montón de carne aullante se revolcaba sobre la escarcha (...). Un soldado cogió un palo y lo hundió en los excrementos. Acercó después el palo a la boca del prisionero. (...) Le untaron los labios varias veces mientras un soldado trataba de abrirle las quijadas. El sargento aprovechó la postura para dar su golpe. Afirmó la punta de la

7 Desde un punto de vista teórico, las contradicciones de la enunciación testimonial están analizadas en Peris Blanes, La imposible voz... siguiendo las ideas de Agamben en Lo que queda... y Derrida (2005) y criticando su deshistorización del testimonio a la luz de las aportaciones de Wieviorka. 
bota en el nacimiento del muslo y con el taco, fuertemente, le golpeó los genitales. Un alarido horroroso taladró la noche. El prisionero saltó y quedó sentado. (...) Los soldados movieron los cordeles. El prisionero cayó de bruces. Lo arrastraron de nuevo, Esta vez hacia las matas de calafates. Allí lo alzaron y lo arrojaron en el mismo centro de los arbustos. El hombre gritó. Miles de espinas se clavaron en su carne. Se agitaba tratando de librarse, pero caía otra vez, sumiéndose en las espinas. Los soldados reían.

Cuando lo sacaron, ya no tenía piel. Era una sola masa de sangre. Los perros se aproximaron y empezaron a lamerlo. Las espinas, clavadas todavía, los hicieron desistir. Por mucho tiempo ese cuerpo conservaría cientos de ellas, y marcas que los meses harían definitivas.(...) Al día siguiente, cuando los presos formaron fila en la mañana para cantar el himno patrio frente al pabellón nacional, inexplicablemente, la bandera no flameaba con la fuerte brisa. Recogida en el mástil parecía congojada, como si dudara entre agitarse o deslizarse sola en posición de duelo. Ese día hubo un fuerte viento en la zona. Llovió también. El agua se deslizó intermitente por las latas del galpón en el regimiento de marinos (47).

Miremos con detenimiento este enigmático final. Tras la descripción pormenorizada y a la vez sutil de esa escena terrible, hay un hiato en la narración y se nos presenta otra escena ("al día siguiente") con unas características totalmente diferentes, pero en la que se hallan presentes, aunque de forma oblicua, los rastros de la violencia extrema que había tenido lugar el día anterior. Si bien ningún elemento se ofrecía para dotar de continuidad a ambas escenas (la de la golpiza y la de la formación en fila ante la bandera), el sosiego aparente de la segunda aparecía atravesado por una tensión diferente. La inmovilidad de la bandera en medio del viento alegoriza una sensación colectiva de abatimiento o duelo atribuible a los efectos de lo representado en la escena anterior.

Ese desplazamiento de la posición afectiva de los detenidos a elementos de la naturaleza o del entorno es propia de una poética que concibe el espacio de la representación como el lugar de una condensación metafórica, en el que la tonalidad emotiva es irradiada hacia todos los elementos de la representación, convirtiéndolos en objetos de un contagio emocional. Así, es la atmósfera del relato la que concentra su significación y a la que se le atribuye la capacidad de producir efectos en el lector: es en el interior de ese ambiente o tono en el que los diversos elementos de la representación cobran sentido. 
Más que eso, los dos últimos párrafos del fragmento seleccionado suponen un importante momento anticlimático con respecto a la escena anteriormente presentada. E implican, además, un rebajamiento del tempo de la narración, que parece detenerse en elementos de poca funcionalidad narrativa pero de una gran significación simbólica. Así, frente a la sucesión de acciones terribles que Quijada nos ha presentado, esos dos breves párrafos tienen la virtud de detener el tiempo de lectura y permitir al lector una reflexión sobre lo que se le ha estado contando, aunque mediada por la amplitud metafórica sobre la que se sostienen.

\section{PRODUCCIÓN DE DOCILIDAD Y ESCRITURA TESTIMONIAL}

En el último de los capítulos de la parte propiamente testimonial del texto, titulado como el conjunto del libro "Cerco de púas", Quijada lleva a cabo en apenas cinco páginas una de las más desoladoras representaciones de la angustia producida por el clima social forjado por la dictadura. Es el texto que, además, hace de transición entre la parte propiamente testimonial y aquella ficcional, señalando la relación entre su salida del campo de concentración en libertad condicional y su decisión de escribir, como modo de transmutar su angustia ante la nueva situación en relatos e imágenes capaces de dar cuenta de ella.

La imagen del 'cerco de púas', extraída de la iconografía concentracionaria, se convierte en metáfora extensible al global del campo social chileno bajo el régimen de Pinochet:

Comprendí después que no estaba libre. Había un cerco que salía de los centros de detención y se prolongaba afuera rodeando la ciudad. Podía verse en las calles alrededor de cada casa, circundando a las personas, con sus púas bien dispuestas. Esas púas habían adquirido variadas formas: patrullaban las calles en oscuros vehículos, apuntaban en las armas amenazadoras de soldados y policías, estaban fijas en las miradas vigilantes, tenían sonidos de metal en los pasos solapados que acosaban, escribían en listas y papeles delatores, tomaban voz y acción en los sucesos de cada hora, en el día y en la noche.

Sí. Estaba libre. Libre para ver y oír y, hasta, para caminar dentro de la ciudad ocupada. Pero casi no podía hablar. (...) Era, ahora, un hombre sellado, mudo. Permanecía dentro de la casa. Nada más. (...) No era imposible que cuando saliéramos instalaran micrófonos. 
Quizás si hasta el teléfono estuviera intervenido. O, tal vez, las cartas eran revisadas (136-7).

Esa extensión metafórica del 'cerco de púas' al global de la sociedad chilena ${ }^{8}$ implica también una transformación en los sujetos que sufrieron su violencia: el sistema represivo chileno no tuvo únicamente como objetivo descolocar, desarticular y maniatar a la oposición política potencial sino que, además, pretendió producir sujetos nuevos, dóciles y moldeables por el poder. Quijada se refiere explícitamente a ello no solamente a través del testimonio de su propio paso por los campos, sino aludiendo a las historias dolorosas de vecinos, compañeros y conocidos que, ya en el exterior del campo de concentración -pero en el interior de ese cerco de púas en que había quedado clausurada la ciudad entera-, habían sido objeto de la política de desapariciones y tortura.

Recuerdo a la joven dirigente universitaria con cara de niña, que desapareció una tarde de una casa del sector. Como a las cuatro, llegó una señora que le rogó la acompañara a un auto, que estaba a la vuelta de la esquina. Le dijo que allá la esperaban unas compañeras de la Universidad que no se atrevían a visitarla. Fue. Iba confiada. En el auto, había dos de sus compañeras de estudios, pero también estaban los hombres de Inteligencia que las habían detenido. Volvió varios días después. Venía extrañamente fría e inexpresiva. Habló una sola vez: 'Mamita -dijo-, he sido violada por doce guardias. Me han tenido tirada en el suelo con piedras sobre los senos. He soportado muchas porquerías en la vagina...' Enseguida buscó el sitio más oscuro de la casa y se quedó ahí por largo tiempo mirando los marcos vacíos de la puerta o las tablas del techo, con los ojos perdidos (138).

Quijada señala recurrentemente el mutismo y el aislamiento como los objetivos centrales del aparato represivo y de ese ideal de docilidad social al que se había consagrado. Ello, que aparece explícitamente tematizado en el texto,

8 La misma metáfora se halla, de otro modo, en el testimonio de Francisco Reyes: "En estos tiempos difíciles salir en libertad no era como para saltar de júbilo. Para el 'delincuente político’ el país entero se había convertido en una cárcel cada vez más grande, en la mayoría de los casos, con mayores riesgos. No sabía en qué hora o día sus pasos serían celosamente vigilados, o cuando una tropa insolente haría una incursión nocturna en su hogar, so pretexto de búsqueda de armas" (138). 
se reafirma por una tonalidad y un ritmo expresivo que refuerzan la sensación desoladora que el sujeto experimentó en esa situación. La representación de su vida en interior, por ejemplo, hace hincapié en la mudez de la experiencia post-concentracionaria, anudada a una existencia 'casi sin ruido', 'sellada', en el que todos los elementos cotidianos se construyen en relación con el terror que generó la presencia vigilante y siniestra de los militares.

En las noches navegaba el sobresalto. Las ráfagas de metralletas, las carreras y gritos, interrumpían el reposo. El insomnio a veces con el rodar de vehículos militares o de Inteligencia que, de improviso, se detenían frente a la casa de un vecino. Entonces eran audibles las pisadas en la acera, los ruidos en la reja, los pasos en el jardín cercano, los golpes en la puerta. Después, la carne castigada, las lamentaciones, el arrastrar de cuerpos por el pavimento (138).

En ese contexto narrativo, las dolorosas historias que resume brillantemente en su breve narración están hiladas por la representación alegórica de la ciudad ocupada por los militares a través de algunos elementos centrales de la iconografía concentracionaria:

Sí, eran púas. Púas y alambre. Podían sentirse con solo ver la ciudad ocupada, mutilada de tantos seres ausentes, de sentimientos olvidados, de vergüenzas perdidas. En las calles, contra los muros, era habitual ver a las nuevas víctimas con las manos en alto, en denigrantes registros. (...) Púas y alambre. Esa era la libertad. Miseria. Miseria de hambre. Miseria que crecía (138-9).

La idea básica es que la ciudad se había convertido en un gran campo de concentración, o lo que es lo mismo, que la lógica del campo se había extendido a todo lo social o, en otras palabras, que la dinámica concentracionaria se había desterritorializado, y que ésta no suponía más una localización dislocante para el orden social ${ }^{9}$, sino que, por el contrario, autonomizándose de un espacio físico (el campo) en el que concentrarse, había acabado por deslocalizarse e invadir con diversas formas e intensidades todas las esferas de lo social,

9 Según la aguda definición de Giorgio Agamben, Estado de excepción... La idea de una desterritorialización del campo de concentración está desarrollada en Peris Blanes, $L a$ imposible voz... 
convirtiéndolas potencialmente en el espacio de una nueva modulación de lo concentracionario.

Es en ese espacio de representación en el que aparece, en el último párrafo, una reflexión sobre la propia producción de escritura, directamente relacionada con esa producción de mudez a la que estaba sirviendo el sistema represivo. Y utiliza para ello una nueva figura alegórica, el perro, que iría a articular la parte específicamente testimonial del texto de aquella otra en que el superviviente testimonia a través de la ficción.

Minutos antes del toque de queda volví a casa apresuradamente. Un perro me alcanzó trotando y caminó a mi lado. Traía las orejas gachas y la cola entre las piernas. Me desentendía de él hasta que metí la llave en la cerradura. Entonces, el animal se pegó a mis piernas y empezó a temblar. Conocía eso. Era miedo. Miedo a lo desconocido. Tal vez ese perro intuía que no llegaría a su refugio. La orden era disparar contra toda forma en movimiento que no contestara el alto. También él, como yo, no podía hablar. Lo dejé entrar. Fue mi asilado hasta el día siguiente. No obstante, me entregó el mensaje. Si era imposible hablar, más tarde o más temprano, podría escribirse. Es lo que hice (139-140).

La asimilación que en ese fragmento tiene lugar entre la experiencia del superviviente en el nuevo espacio social chileno y la figura alegórica del perro cifra las razones de la escritura testimonial y/o literaria. De hecho, la escritura aparece como el espacio en el que esa mudez $-\mathrm{y}$ por tanto ese aislamiento social que la mudez sintomatizaba-podía ser recusada. Ello produce, además, dos efectos fundamentales: supone, por una parte, una recusación en toda regla de la imposición del silencio que llevaban a cabo los militares; por otra parte, abre un espacio para que esa experiencia desoladora de la disgregación social por el terror pudiera ser, aunque precariamente, elaborada.

En la lógica de la narración global (aunque ésta hubiera carecido de continuidad), esta escena postrera tiene, además, el valor de permitir la relectura de todo lo que le antecede, a la luz de ella, esto es, de iluminar tanto los acontecimientos narrados como el sentido de la propia escritura en el contexto y la situación en que se habían producido. No es, ni mucho menos, el único testimonio en el que se construye una escena, dentro de la narración, en la que se pone de manifiesto el sentido de la propia enunciación testimonial; pero el texto de Quijada introduce una lógica que sí es ajena a la mayoría de los testimonios de supervivientes, ya que tras esa breve escena 
en la que por primera vez aparece un perro, se abría otro espacio narrativo -titulado explícitamente "Paréntesis de perros"-, marcando editorialmente la diferencia con lo anterior. Este nuevo espacio narrativo se regirá por leyes de sentido muy diferentes a lo que hasta ahora había tenido lugar en el texto testimonial, si bien desarrolla hasta llevar a un punto extremo algunos de los procedimientos que en éste se habían esbozado.

Las dos últimas frases del fragmento anterior -"Si era imposible hablar, más tarde o más temprano, podría escribirse. Es lo que hice"- mantienen una cierta indeterminación con respecto al objeto al que refieren. Es decir, esa escritura a la que Quijada daba el valor implícito de recusar la mudez obligatoria ¿era la escritura testimonial que nos había presentado hasta ese momento, o las breves ficciones caninas que incluiría en la segunda parte?

\section{TESTIMONIO, FICCIÓN Y ALEGORÍA}

Si bien entre ambas partes del texto hay una evidente diferencia en el modo de composición, en el sujeto que enuncia y en su forma de producir sentido -separación que se refuerza a través de la disposición editorial en partes diferenciadas- lo cierto es que ambas parecen responder a un idéntico impulso. Es más, pareciera que ese 'paréntesis sobre perros' surgiera del interior del propio texto testimonial, como una forma otra de condensar en el lenguaje esa experiencia desoladora de la que nos había hablado durante todo el libro. Lo cierto es que a la vez testimonio y ficción entraban en una zona de indeterminación, en la que los procedimientos figurativos y de organización narrativa eran intercambiables, así como la ética de la enunciación que a ambos sostenía.

Señala Idelbel Avelar (221 y ss.) que la alegoría es la faz estética de la derrota política, y que a través de grandes máquinas alegóricas las literaturas postdictatoriales han intentado elaborar mecanismos de representación de una catástrofe que parecía irrepresentable. Por supuesto que las breves ficciones de Quijada no pueden ser comparadas con esas formidables invenciones de mundos alegóricos ${ }^{10}$; son, por el contrario, historias verosímiles, instaladas

10 En el caso chileno se podrían enumerar diferentes casos, pero el ejemplo más obvio de esta tendencia alegórica sería la gran novela de José Donoso, Casa de Campo (1978), en la que se establece una relación de equivalencias fantasmagóricas entre los acontecimientos 
en un código realista; pero, sin embargo, hay algo en ellas que, sin romper su íntima conexión con la enunciación y la ética del testimonio, las acerca a esa deriva alegórica que, en palabras de Avelar, sería la 'expresión estética de la desesperanza'.

Los perros de las breves ficciones de Quijada son personajes que no rompen en ningún momento la clave realista de su testimonio, sino que, por el contrario, la refuerzan, permitiendo que el texto detuviera su mirada en paisajes urbanos desvencijados y carentes de cualquier confort. En ningún caso, pues, ese recurso de focalización quiebra la verosimilitud, como ocurre en la alegoría clásica. Sin embargo, la asimilación que en el capítulo anterior se había producido entre el perro y el superviviente (al compartir su miedo, su frío y su mudez) no abandonará la conciencia del lector durante la lectura del texto.

Más que eso, focalizar la atención narrativa en los perros permite a Quijada recorrer un paisaje urbano frío y lleno de despojos, una geografía devastada e inhumana, en el que solo la actitud leal y fiel de los perros hacia sus amos (algunos de ellos desaparecidos o encerrados en campos de concentración) aparece como un repunte de dignidad en ese campo baldío. En esas breves historias de perros, Quijada nos detalla, pues, un paisaje social que había pasado a confundirse con sus ruinas. Tal como señaló en su estudio sobre el drama barroco Walter Benjamin, la alegoría es ese extraño entrecruzamiento de naturaleza e historia en la que ésta se presenta como "paisaje primordial petrificado" (Avelar 22111). Esto es, el lugar de una mirada en que la historia se suspende y es contemplada en la cristalización de sus ruinas, en el momento mismo en que estas comienzan a confundirse con la naturaleza:

La alegoría es la faz estética de la derrota política -véase la relación entre el barroco y la contrarreforma, la poesía alegórica de Baudelaire y el Segundo Imperio, la valencia actual de la alegoría en la posmodernidad-no gracias a algún agente extrínseco, controlador, sino porque las imágenes petrificadas de las ruinas, en su inmanencia,

que tienen lugar en el interior de la familia de los Ventura y la trayectoria de Chile desde Allende a Pinochet.

11 Según Benjamin "a los escritores barrocos... la naturaleza no les aparecía en capullo y floración, sino en la sobremaduración y decaimiento de sus creaciones. En la naturaleza veían lo eterno transitorio, y solo aquí reconocía la historia la visión saturnina de esta generación" (citado por Avelar 2000: 221). 
conllevan la única posibilidad de narrar la derrota. Las ruinas serían la única materia prima que la alegoría tiene a su disposición (Avelar 222).

Así pues, esa insistencia en las ruinas de un proyecto histórico y en los despojos que la represión militar estaba dejando como saldo es lo que conecta los breves relatos de Quijada con esa deriva alegórica a partir de la cual otra serie de ficciones tratarían de dar cuenta de la enormidad de la catástrofe que había tenido lugar. De un modo mucho más modesto, e íntimamente ligadas a la poética testimonial de la que surgían, algunas de las breves historias de perros de Quijada se detienen en las ruinas no solo del espacio social arrasado por la violencia de Estado, sino en aquellas del cuerpo maltratado y torturado, en la materialidad vaciada de sentido del cadáver.

La estrecha imbricación que esos cuerpos sin vida, convertidos en mera carne destruida, mantienen con el paisaje natural en que aparecen y la descripción pegadísima al detalle que Quijada realiza de algunas de sus partes, inscriben la representación en un registro diferente a aquel en el que se habían organizado las demás narraciones testimoniales. Esa insistente focalización en el cadáver se sitúa mucho más allá de la funcionalidad narrativa y ubica la descripción en un paradigma menos cercano a la idea de registro o captación que al de la metáfora o la alegoría.

Es de ese modo, que linda con los procedimientos de las representaciones alegóricas que Benjamin analizó, cómo desde el interior de la voz testimonial se abre paso una lógica diferente. Una lógica en la que a través de la exploración de esos cuerpos desmembrados, que habían sido portadores de los grandes proyectos de transformación social que en ese momento ya habían caído, la ficción trata de retener algo de la naturaleza terrible de lo acontecido, y que ya es únicamente legible en las huellas que ha dejado. O lo que es lo mismo, en esas sus ruinas -ya fuera en forma de cuerpos despedazados, de afectos destruidos o de espacios arrasados- poco a poco se irían convirtiéndo en un 'paisaje primordial petrificado'.

El sol ya apuntaba sobre la alta y nevada cordillera. El amanecer se extendía en ese extenso Valle en que don Pedro de Valdivia fundara un día la ciudad de Santiago del Nuevo Extremo. Las aguas del río Mapocho, que atravesaba la ciudad en ese rodar sin fin de aguas cordilleranas, traía sorpresas esta madrugada: cadáveres.

Unos boca abajo mostrando la nuca destruida, los cabellos pegoteados, la piel hinchada; otros, cara al cielo, con los enormes ojos 
abiertos en muda interrogación. Algunos se deslizaban serenamente, en filas, como si fueran a una concentración. Otros iban dando tumbos, golpeándose en las defensas de concreto.

Eran cadáveres de obreros -seguramente mineros-, acribillados. En muchos casos, mostraban un orificio en medio de la frente, que se perfilaba claramente, señalando el punto preciso de su muerte.

Un perro grande, de largas y caídas orejas, corría por la ladera, por los vericuetos de la ribera. Emitía cortos y lastimeros aullidos. Cuando el cuerpo se estrellaba casi junto a él, pegaba saltos asustados y ladraba furiosamente. Por varias cuadras brincó entre las piedras. En un recodo de las aguas alcanzó al fin lo que buscaba. Era el cuerpo de un muchacho que parecía esperarlo, detenido contra unas rocas.

El perro se echó al agua. Llegó hasta el cadáver y empezó a tirar de sus ropas. Trabajó largo rato. Los trapos se desprendían obstaculizando su faena y no conseguía afirmar el cuerpo que tendía a seguir su viaje por la corriente. Lo logró después de un rato. Con su pecho y las patas delanteras, estabilizó el cadáver, que quedó de espaldas sobre los pedruscos. La piel era blanca y marcada por anchas moraduras. En el rostro, los ojos claros, abiertos, llevaban el asombro del cielo en sus pupilas.

El perro lamió una de las manos. Luego acercó su hocico a la cara y se mantuvo un instante contemplándola. Con una de sus patas delanteras, intentó moverla, en bruscas caricias, como incitándole a despertar. Después con la lengua afuera, movió la cabeza en todas direcciones. Ladró, enseguida, desesperadamente. Luego colocó sus patas en el pecho del muerto, alzó el hocico al cielo y aulló largamente.

A su lado, seguían flotando los cadáveres.

\section{CONCLUSIÓN}

Como otros muchos testimonios, el texto de Quijada fue publicado en un contexto turbulento, en que tanto los dirigentes del exilio chileno como los integrantes de la vanguardia cultural latinoamericana trataban de apropiarse y llevar a su campo de acción los testimonios de los supervivientes chilenos. En ese contexto de fuerte expectativas y de profunda imbricación del campo cultural y político, textos como el de Quijada articularon estrategias ambivalentes que, a la vez que se alineaban con las luchas políticas del exilio y trazaban representaciones funcionales a sus intereses, exploraban las posibilidades literarias del testimonio. 
Para ello, el texto de Quijada incorporó, como otros testimonios, procedimientos y operatorias propias de la literatura moderna y los reelaboró de acuerdo con los propósitos de su escritura. De ese modo, además de denunciar y dar visibilidad a la represión chilena, sometió explícitamente su escritura a un trabajo estético que acercó algunos de sus textos a la deriva alegórica que, tras la caída de los grandes proyectos de emancipación continental, había ganado a buena parte de la producción literaria latinoamericana.

Este artículo ha tratado de analizar y contextualizar ese proceso. Quedaría pendiente analizar si fue ese un rasgo compartido con otras poéticas testimoniales y si, del otro lado, la literatura ficcional sufrió también trasvases y contagios de los elementos composicionales y enunciativos de este tipo de testimonios que, como se ha visto, consiguió en los años setenta una fuerte irradiación tanto en el campo político como en el cultural.

\section{BIBLIOGRAFÍA}

Agamben, Giorgio. Lo que queda de Auschwitz. El archivo y el testigo. Homo Sacer III. València: Pre-Textos, 2000.

Estado de excepción. Homo sacer II. València: Pre-Textos, 2004.

Avelar, Idelbel. "Pensamiento postdictatorial y caída en la inmanencia" Dialectos en transición. Politica y subjetividad en el Chile actual. Coord: Mauro Salazar y Miguel Valderrama. Santiago de Chile: LOM, 2000. 213-240.

Avelar, Idelbel. Alegorías de la derrota: la ficción postdictatorial y el trabajo del duelo. Santiago de Chile: Cuarto Propio, 2000.

Carrasco, Rolando. Prigué. Moscú: Novosti, 1977.

Derrida, Jacques. Poétique et politique du témoignage. Paris : L’Herne, 2005.

Dorfman, Ariel. "Código político y código literario: el género testimonio en Chile hoy". Testimonio y literatura (Jara, René y Hernán Vidal). Minessota: Institute for the studies of ideologies and literature, 1986. 170-234.

Fornet, Jorge. "La Casa de las Américas y la ‘creación' del género testimonio”. Casa de las Américas 200 (1995): 120-121. La Habana.

Gilman, Claudia. Entre la pluma y el fusil. Debates y dilemas del escritor revolucionario en América Latina. Buenos Aires: Siglo XXI, 2003.

Peris Blanes, Jaume. La imposible voz. Memoria y representación de los campos de concentración en Chile: la posición del testigo. Santiago de Chile: Cuarto Propio, 2005.

Historia del testimonio chileno. De las estrategias de denuncia a las politicas de memoria. Valencia: Anejos de Quaderns de Filologia, 2008.

Quijada Cerda, Aníbal. Cerco de púas. La Habana: Casa de las Américas, 1977. 
Reyes, Francisco. Testigo presencial. Quito: Editorial 4 de Septiembre, 1981. Reedición: Santiago de Chile: Fértil Providencia, 1991.

Unnold, Yvonne S. Representing the unrepresentable. Literature of trauma under Pinochet in Chile. New York: Peter Lang, 2002.

Valdés, Hernán. Tejas Verdes. Diario de un campo de concentración en Chile. Barcelona: Ariel, 1974.

Vega, Luis. La caída de Allende. Anatomía de un golpe de estado. Jerusalén: La Semana, 1983.

V.V.A.A. "Conversación en torno al testimonio". Casa de las Américas 200 (1995): 122-124. La Habana.

Wieviorka, Annette. L'ère du témoin. Paris: Plon, 1998. 